(C) [2009] IEEE. Reprinted, with permission, from Guo, Youguang; Zhu, Jianguo; Lu, Hai Yan; Wang, Yi; Jin, Jianxun. 2009, 'Design and Analysis of a Permanent Magnet Motor with Soft Magnetic Composite Core for Driving Dishwasher Pump', Proceedings of IEEE International Conference on Applied Superconductivity and Electromagnetic Devices, pp. 138-141.This material is posted here with permission of the IEEE. Such permission of the IEEE does not in any way imply IEEE endorsement of any of the University of Technology, Sydney's products or services. Internal or personal use of this material is permitted. However, permission to reprint/republish this material for advertising or promotional purposes or for creating new collective works for resale or redistribution must be obtained from the IEEE by writing to pubs-permissions@ieee.org. By choosing to view this document, you agree to all provisions of the copyright laws protecting it. 


\section{Design and Analysis of a Permanent Magnet Motor with SMC Core for Driving Dishwasher Pump}

\author{
Youguang Guo, Jianguo Zhu, Haiyan Lu, Yi Wang \\ Faculty of Engineering and Information Technology \\ University of Technology Sydney \\ Sydney, Australia \\ youguang@eng.uts.edu.au, joe@eng.uts.eud.au, \\ helenlu@it.uts.edu.au, yiwang@eng.uts.edu.au
}

\begin{abstract}
This paper presents the development of a permanent magnet motor with soft magnetic composite (SMC) stator core for driving a dishwasher pump. The unique properties of the SMC, such as 3D magnetic isotropy and molding production technique, have been taken into account in the design. 3D magnetic field finite element analysis is carried out to accurately compute the motor parameters and an equivalent electrical circuit is derived to predict the motor performance. Analysis results show that the developed motor is appropriate.
\end{abstract}

Keywords-permanent magnet motor; soft magnetic composite (SMC) core; design; magnetic field finite element analysis

\section{INTRODUCTION}

SMC (soft magnetic composite) materials and SMC electrical machines have experienced significant development in the past decade [1]. The main attractive features include great design flexibility brought by the material's 3D magnetic isotropy and negligible eddy current loss, and great potential of low cost mass production brought by the powder metallurgical process. The application of SMC removes the restraints on the design and manufacturing of conventional electrical machines with laminated electrical steels, in which the magnetic flux must flow within the lamination plane because the flux component perpendicular to the plane may cause excessive core loss. A large amount of research work has been conducted by various researchers on designing and prototyping various types of electrical machines and the results appear quite promising [2-10]. Among the many types of electrical machines, those with complex structure and 3D flux path may take the most advantages of the material.

In this paper, a small permanent magnet (PM) motor with SMC stator core is designed for replacing the induction motor in a dishwasher pump and hence the design aim is to produce the same output subject to the existing space envelop. By taking the unique properties of the SMC, such as $3 \mathrm{D}$ magnetic isotropy, the PM stator is designed axially longer than the stator and hence 3D numerical analysis of magnetic field such as finite element analysis (FEA) is necessary for accurately computing the field distribution and key motor parameters. An equivalent electrical circuit is derived to predict the motor performance. Optimization is conducted for minimizing the cost of effective materials. Furthermore, a phase variable model is built in Simulink for predicting the motor's dynamic

\author{
Jianxun Jin \\ Center of Applied Superconductivity and Electrical \\ Engineering \\ University of Electronic Science and Technology of China \\ Chengdu, China \\ jxjin@uestc.edu.cn
}

performance. The analysis results show that the designed motor could successfully drive the dishwasher pump.

\section{MOTOR PROTOTYPE}

Fig. 1(a) shows the schematic structure of the motor prototype (half), where the SMC stator core consists of 6 cylindrical teeth and the PM rotor consists of 4 ferrite magnets. 6 coils are wound around the stator teeth and are connected to form a 3-phase star winding, which is supplied by an inverter with the standard 240 VAC single phase power source. The major motor dimensions include $43 \mathrm{~mm}$ for the stator inner diameter, $100 \mathrm{~mm}$ for the stator outer diameter, $14 \mathrm{~mm}$ for the stator axial length, and $2.35 \mathrm{~mm}$ for the main air gap. The motor is designed to operate under a sensorless brushless DC control scheme, delivering an output of $60 \mathrm{~W}$ at $3000 \mathrm{rev} / \mathrm{min}$.

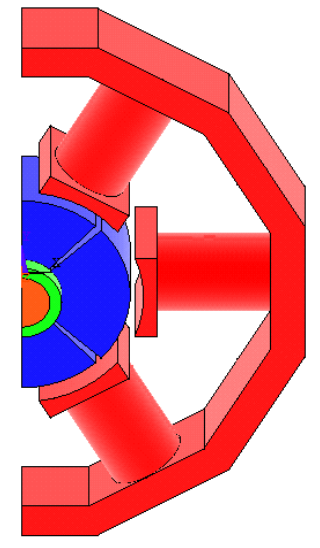

(a)

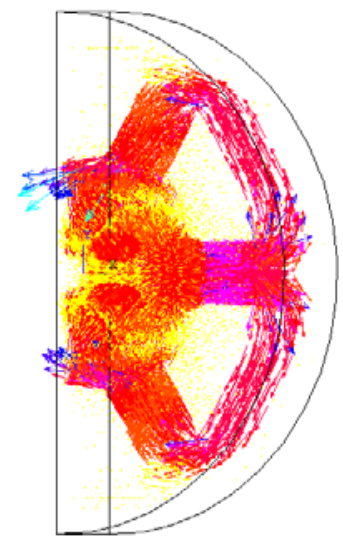

(b)

Figure 1. Motor prototype: (a) schematic structure, (b) no-load field distribution

To minimize the change for best utilization of the existing manufacturing devices and techniques, the PM rotor structure has been kept the same as that of the existing silicon steel pump motor, and the air gap is also kept as the original size of the silicon steel motor. It is assumed that the PMs are magnetized after the rotor assembly, which is magnetically equivalent to the Halbach magnet structure except that the magnet anisotropy was not aligned with the magnetization direction. 
In order to maintain the flux linkage of the stator winding, and hence the induced electromagnetic force, such that the inverter does not have to change, the cross section of the stator poles is changed to cylindrical with a diameter of $14 \mathrm{~mm}$, which results in an area of $154 \mathrm{~mm}^{2}$. In order to attract as much rotor PM flux as possible to the stator poles, the cross sectional area of the stator pole shoes is increased to $16 \times 18 \mathrm{~mm}^{2}$. Besides the magnetic consideration, the cross sectional area of the yoke is increased further to $6 \times 14 \mathrm{~mm}^{2}$ for higher mechanical strength. As shown in Fig.1(b), these measures have been successful in attracting the rotor PM flux and guiding the magnetic flux in the SMC stator core.

\section{MAGNETIC FIELD FEA AND PARAMETER COMPUTATION}

\section{A. No-load Magnetic Field FEA}

Considering the 3D flux feature, 3D magnetic field FEA has been conducted to work out the magnetic field distribution and key motor parameters such as winding flux, back electromotive force (emf), cogging torque, core loss and winding inductance. For example, Fig. 1(b) illustrates the vector plots of magnetic field under no-load, where the vector length is proportional to the flux density magnitude. From the no-load field solution, the flux of the stator winding produced by the rotor PMs can be obtained as shown in Fig. 2. The peak value of the flux, which occurs when the axes of a rotor PM and a stator pole are aligned, is $0.076 \mathrm{mWb}$, and the peak value of air gap flux density is $0.33 \mathrm{~T}$. Therefore, the same number of turns, 450 turns each coil, is chosen to maintain the same back emf as the silicon steel motor.

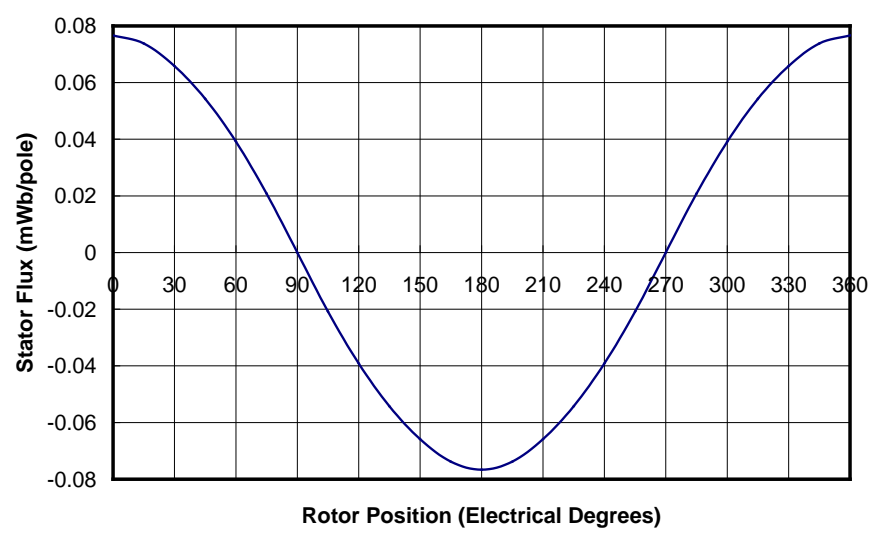

Figure 2. Stator magnetic flux due to rotor PMs versus rotor position

\section{B. Calculation of Parameters}

The emf and torque constants, $K_{E}$ and $K_{T}$, can be calculated once the flux linkage of the stator winding is available as the following:

$$
\begin{gathered}
K_{E}=\frac{P}{2} N_{s} \frac{\phi_{\max }}{\sqrt{2}} \\
K_{T}=m K_{E}
\end{gathered}
$$

where $P$ is the number of poles, $N_{s}$ the number of turns of a stator phase winding, $\phi_{\max }$ the peak value of the magnetic flux linking the phase winding, and $m$ the number of phases. For this SMC motor, the rated emf is $30.4 \mathrm{~V}$ at $3000 \mathrm{rev} / \mathrm{min}$, and the rated torque is $0.19 \mathrm{Nm}$ with a current of $0.66 \mathrm{~A}$.

The number of turns and the wire diameter of the stator winding can be chosen through a comprehensive consideration of the terminal voltage, efficiency, and available space for the stator windings. For this SMC motor, they are chosen as 450 turns per coil, or 900 turns per phase winding, and $0.36 \mathrm{~mm}$ enamelled copper wire. The fill factor is $48 \%$, slightly higher than that of the existing silicon steel motor. The corresponding stator phase winding resistance is $11.3 \Omega$.

The self and mutual inductances were calculated as 19.70 $\mathrm{mH}$ and $6.02 \mathrm{mH}$, respectively, by a modified incremental energy method [11]. The numerical procedure of this method is as the following: (1) For a given rotor position, perform a nonlinear analysis considering the saturation due to the rotor PMs; (2) Save the incremental permeability in each element; (3) "Switch off" the rotor PMs, and perform a linear field analysis with the saved permeabilities under perturbed stator current excitations, i.e. assigning the 3 phase winding currents as $\left(i_{a}, i_{b}, i_{c}\right)=(\Delta i, \Delta i, 0),(\Delta i, 0, \Delta i),(0, \Delta i, \Delta i),(\Delta i, 0,0),(0,0, \Delta i)$, and $(0, \Delta i, 0)$, respectively; (4) Calculate the value of the incremental magnetic co-energy for each current excitation; (5) Calculate the self and mutual incremental inductances by

$$
\begin{aligned}
& L_{a a}(\theta)=L_{b b}(\theta)=L_{c c}(\theta)=\frac{2 W_{c}(\Delta i, 0,0, \theta)}{(\Delta i)^{2}} \\
& L_{a b}(\theta)=L_{b a}(\theta) \\
& =\frac{W_{c}(\Delta i, \Delta i, 0, \theta)-W_{c}(0, \Delta i, 0, \theta)-W_{c}(\Delta i, 0,0, \theta)}{(\Delta i)^{2}} \\
& L_{b c}(\theta)=L_{c b}(\theta) \\
& =\frac{W_{c}(0, \Delta i, \Delta i, \theta)-W_{c}(0, \Delta i, 0, \theta)-W_{c}(0,0, \Delta i, \theta)}{(\Delta i)^{2}} \\
& L_{c a}(\theta)=L_{a c}(\theta) \\
& =\frac{W_{c}(\Delta i, 0, \Delta i, \theta)-W_{c}(0,0, \Delta i, \theta)-W_{c}(\Delta i, 0,0, \theta)}{(\Delta i)^{2}}
\end{aligned}
$$

Due to the structural symmetry, it is only required to rotate the rotor for half of a pole pitch to find out the relations between the self and mutual inductances and the rotor position. For this particular motor, the inductances are found approximately constant.

The core loss is an important factor in SMC motor design. In the finite element analysis, the motor total core is calculated by summing up the core loss of each element, and in each element, the core loss attributed to hysteresis, eddy current and anomalous losses. For accurate prediction of core losses, the locus of the rotating magnetic flux density vector is calculated by rotating the rotor for a tooth pitch, and the Fourier series is employed to analyze the effect of harmonics. The method for accurate prediction of core losses in SMC motors with 3D magnetic fields is presented in detail in [12-13]. The core loss of this SMC pump motor is $2.89 \mathrm{~W}$ at $3000 \mathrm{rev} / \mathrm{min}$. 
The cogging torque versus rotor position was also calculated, but it was found very small with a maximum value of $0.01 \mathrm{Nm}$.

\section{Design Optimization and Cost}

A hybrid optimization technique using 3D finite element analysis with increasing accuracy [14] was employed to optimize the stator dimensions for lowest material cost. For this SMC pump motor, only the effective material cost was calculated, whereas the manufacturing cost was not included as it is not very clear at this stage. The effective material cost for this SMC pump motor is AUD2.00, assuming AUD2 per kg for SMC, AUD7.5 per kg for enameled copper wire, and AUD4 per kg for ferrite PM.

\section{Temperature Rise}

A simple thermal analysis based on thermal circuit was conducted to verify the temperature rise of the motor. Fig. 3(a) shows the simple thermal network used for this analysis. The thermal conductivities are chosen as $380 \mathrm{~W} / \mathrm{mK}$ for copper, 20 $\mathrm{W} / \mathrm{mK}$ for SMC, $0.15 \mathrm{~W} / \mathrm{mK}$ for insulator, and $0.027 \mathrm{~W} / \mathrm{mK}$ for air. The convection coefficient on the motor surface is chosen as $97.10 \mathrm{~W} /\left(\mathrm{m}^{2} \mathrm{~K}\right)$ [15], and the thickness of the insulator is assumed to be $1 \mathrm{~mm}$. Fig. 3(b) shows the thermal resistances and the temperature rises at various parts of the motor. As shown, the temperature rise is $90{ }^{\circ} \mathrm{C}$ in the middle of the stator coil, and $65^{\circ} \mathrm{C}$ in the middle of the stator pole.

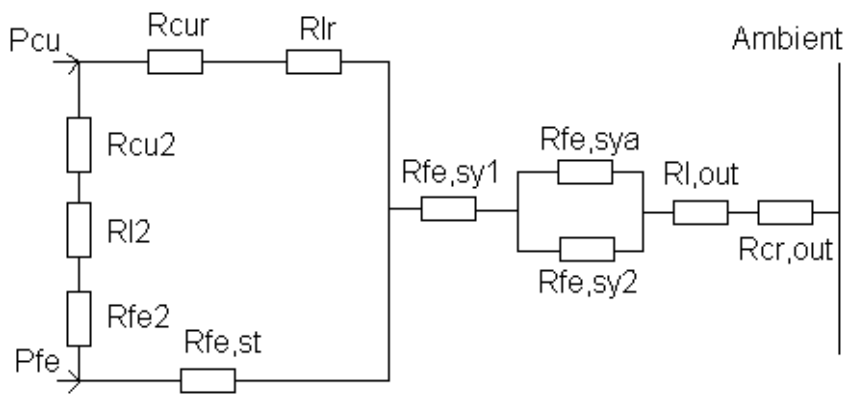

(a)

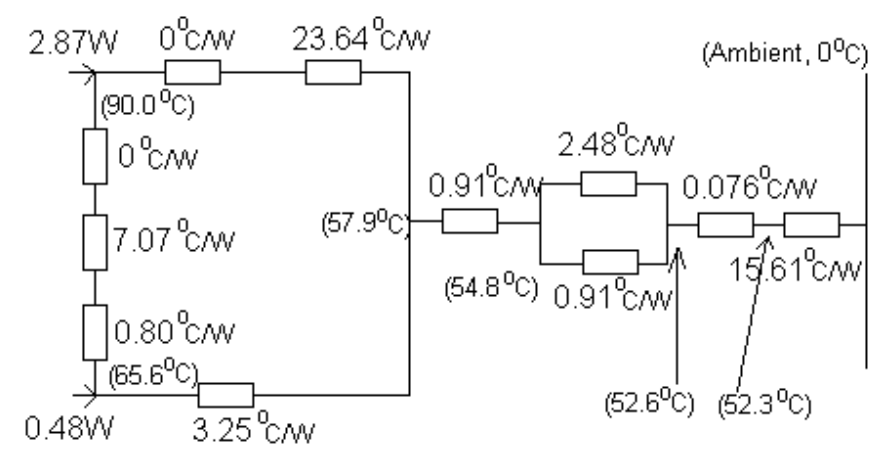

(b)

Figure. 3. (a) A simple thermal network, and (b) thermal resistances and temperature rises in various parts of the SMC pump motor

\section{Motor PERFormance Prediction}

Fig. 4 illustrates the per phase equivalent electrical circuit, where $E_{a}, R_{a}$, and $L_{s}$ are the back emf, stator winding resistance, and synchronous inductance which equals the self inductance plus half of the mutual inductance, and $V_{a}$ and $I_{a}$ are the stator terminal voltage and phase current, respectively. The optimum brushless DC operating mode, i.e. $I_{a}$ is in phase with $E_{a}$, is assumed for this SMC pump motor and the steady-state mechanical characteristic, i.e. the relation between the rotor speed and electromagnetic torque, can be derived as

$$
n=\frac{30}{\pi} \frac{\sqrt{\left(\frac{R_{a} T_{e m}}{m}\right)^{2}+\left[\left(\frac{P}{2} L_{s} \frac{T_{e m}}{K_{T}}\right)^{2}+K_{E}^{2}\right]\left[V_{a}^{2}-\left(\frac{R_{a} T_{e m}}{K_{T}}\right)^{2}\right]}-\frac{R_{a} T_{e m}}{m}}{\left(\frac{P}{2} L_{s} \frac{T_{e m}}{K_{T}}\right)^{2}+K_{E}^{2}}
$$

where $m=3$ is the number of phases, and $P=4$ the number of poles. Fig. 5 illustrates the torque/speed curves of the SMC pump motor with different values of terminal voltage.

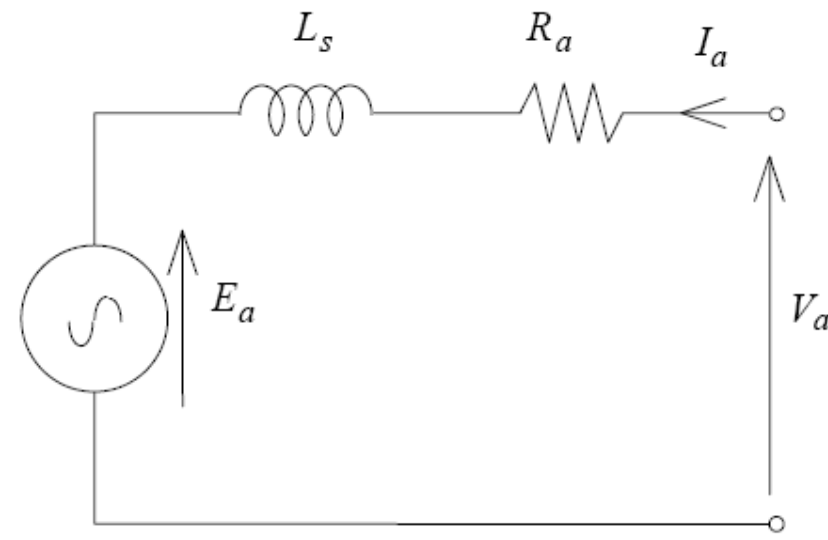

Figure 4. Per phase equivalent electrical circuit

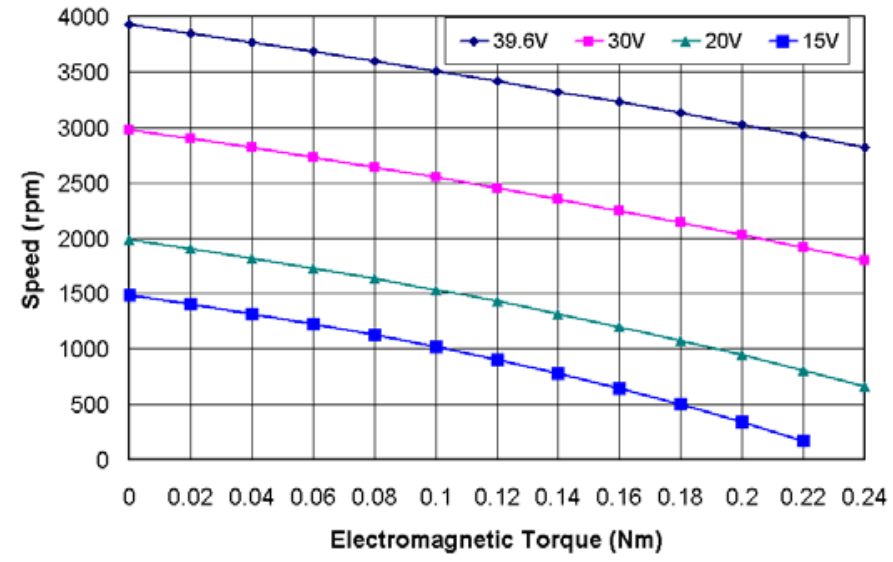

Figure 5. Torque/speed curve of SMC pump motor

The input power, output power, and efficiency can be computed by

$$
\begin{gathered}
P_{\text {in }}=P_{\text {em }}+P_{\text {cu }}=m E_{a} I_{a}+m I_{a}^{2} R_{a} \\
P_{\text {out }}=P_{\text {em }}-P_{\mathrm{Fe}}-P_{\text {mec }} \\
\eta=P_{\text {out }} / P_{\text {in }}
\end{gathered}
$$

Fig. 6 illustrates the curves of the input and output powers and efficiency versus the torque and rotor speed when the terminal voltage is $39.6 \mathrm{~V}$ (rms), respectively, of the SMC 
pump motor. In the optimum brushless DC operating mode, this SMC pump motor can output $60 \mathrm{~W}$ with an efficiency of $73 \%$ at $3000 \mathrm{rev} / \mathrm{min}$ when the terminal voltage is $39.6 \mathrm{~V}$ (rms).

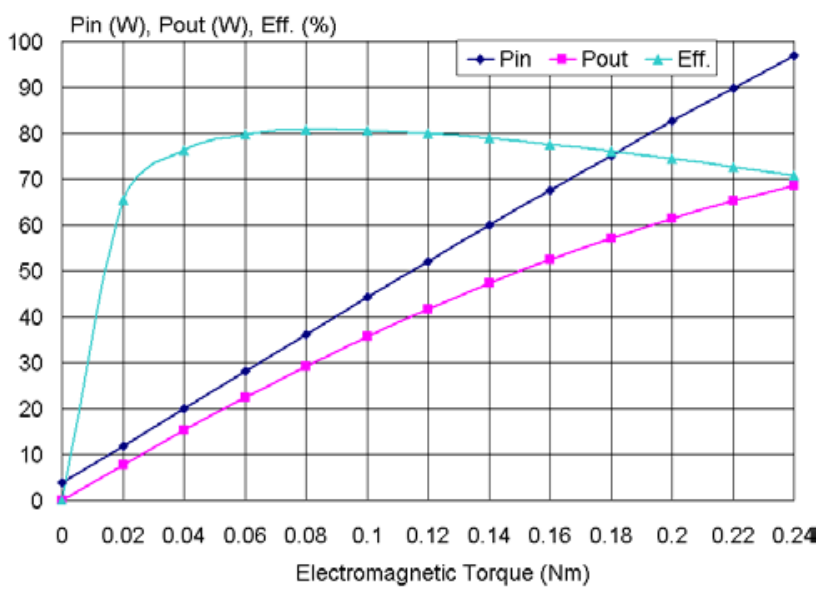

(a)

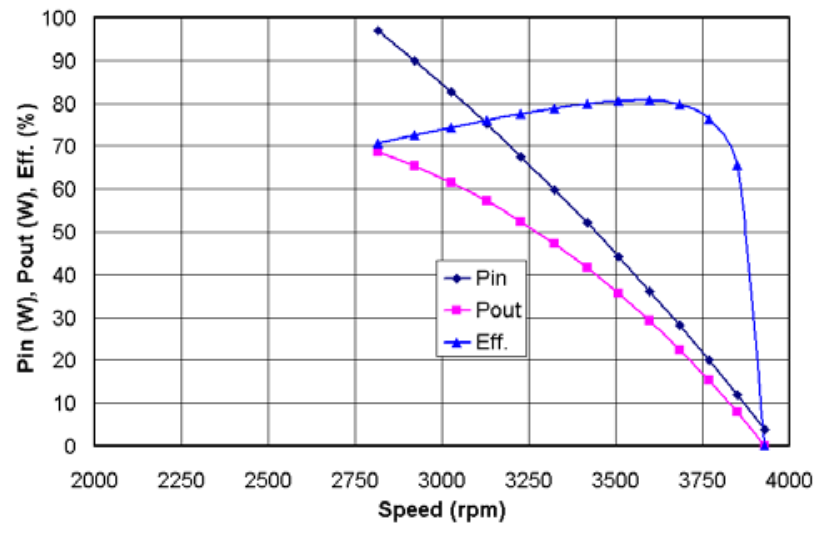

(b)

Figure 6. Input and output powers and efficiency of SMC pump motor versus (a) torque, and (b) rotor speed

\section{CONCLUSION}

To investigate the application of SMC material in industry, this paper reports the design and analysis of a PM SMC motor for driving a dishwasher pump. The unique properties, such as magnetic isotropy and molding process, of the SMC have been taken into account in the motor design. 3D magnetic field finite element analysis is conducted to accurately determine the magnetic field distribution and key motor parameters. An equivalent electrical circuit is derived for predicting the motor performances and the results show that the designed motor would be successful for driving the dishwasher pump.

\section{REFERENCES}

[1] The latest development in soft magnetic composite technology, SMC Update - Reports of Höganäs AB, Sweden, 1997-2009, available at http://www.hoganas.com/.

[2] M. Persson, P. Jansson, A.G. Jack, and B.C. Mecrow, "Soft magnetic composite materials - use for electrical machines," in Proc. $7^{\text {th }}$ IEE Conf on Electrical Machines and Drives, Durham, England, 1995, pp. 242246.

[3] A.G. Jack, "Experience with the use of soft magnetic composites in electrical machines,” in Proc Int. Conf. on Electrical Machines, Istanbul, Turkey, 1998, pp. 1441-1448.

[4] F. Profumo, A. Tenconi, Z. Zhang, and A. Cavagnino, "Novel axial flux interior PM synchronous motor realized with powdered soft magnetic materials,” in Proc. $33^{\text {rd }}$ IEEE Ind. Applications Society Annual Meeting, St. Louis, USA, 1998, pp. 152-158.

[5] R. Blissenbach, G. Henneberger, U. Schafer and W. Hackmann, "Development of a transverse flux traction motor in a direct drive system,” Int. Conf. on Electrical Machines, Helsinki, Finland, 2000, pp. 1457-1460.

[6] J. Cros, P. Viarouge and A. Halila, "Brush DC motors with concentrated windings and soft magnetic composites armatures," in Proc. IEEE $36^{\text {th }}$ Industry Application Society Annual Meeting, Chicago, USA, 2001, pp. 2549-2556.

[7] Y.G. Guo and J.G. Zhu, "Application of soft magnetic composite materials in electrical machines, a review," Australian Journal of Electrical \& Electronics Engineering, Vol. 3, No. 1, pp. 37-46, 2006.

[8] M. Khan, Y. Chen, and P. Pillay, "Applications of soft magnetic composites to PM wind generator design," in Proc. IEEE Power Engineering Society General Meeting, June 2006, pp. 1-4.

[9] G.S. Liew, N. Ertugrul, W.L. Soong, and J. Gayler, “An investigation of advanced magnetic materials for axial field brushless permanent magnet motor drives for automotive applications," in Proc. $37^{\text {th }}$ IEEE Power Electronics Specialists Conference, June 2006, pp. 1-7.

[10] G. Cvetkovski and L. Petkovska, "Performance improvement of PM synchronous motor by using soft magnetic composite material,” IEEE Trans. Magn., Vol. 44, No. 11, pp. 3812-3815, Nov. 2008.

[11] Y. G. Guo, J. G. Zhu, and H. Y. Lu, “Accurate determination of parameters of a claw pole motor with SMC stator core by finite element magnetic field analysis,” IEE Proceedings - Electric Power Application, Vol. 153, No. 4, pp. 568-574, July 2006.

[12] J.G. Zhu and V.S. Ramsden, "Improved formulations for rotational core losses in rotating electrical machines,” IEEE Trans. Magn., Vol. 34, No. 4, pp. 2234-2242, July 1998.

[13] Y.G. Guo, J.G. Zhu, J.J. Zhong, and W. Wu, "Core losses in claw pole permanent magnet machines with soft magnetic composite stators," IEEE Trans. Magn., Vol. 39, No. 5, pp. 3199-3201, Sept. 2003.

[14] Y.G. Guo, J.G. Zhu, and H.W. Lu, "Design of SMC motors using hybrid optimization techniques and 3D FEA with increasing accuracy," in Proc. Int. Conf. on Electrical Machines and Systems, Nanjing, China, Sept. 2005, pp. 2296-2301.

[15] Y.G. Guo, J.G. Zhu, and W. Wu, "Thermal analysis of SMC motors using a hybrid model with distributed heat sources," IEEE Trans. Magn., Vol. 41, No. 6, pp. 2124-2128, June 2005. 